\title{
Detection and characterization of chicken astrovirus associated with hatchery disease in commercial day-old turkeys in southwestern Nigeria
}

\author{
Adebowale I. Adebiyi ${ }^{1,3} \cdot$ Kerry Mcilwaine ${ }^{2} \cdot$ Daniel O. Oluwayelu ${ }^{1} \cdot$ Victoria J. Smyth $^{3}$
}

Received: 25 July 2020 / Accepted: 25 January 2021 / Published online: 23 March 2021

(c) The Author(s), under exclusive licence to Springer-Verlag GmbH Austria, part of Springer Nature 2021

\begin{abstract}
Infectious diseases are a major obstacle to profitable poultry production in Nigeria due to the mortality and severe economic losses they cause. In particular, they are a potent threat to attainment of the food security goals of government and national self-sufficiency in food production. Thus, there is a need for continuous monitoring of the nation's poultry population for these diseases. As part of an ongoing investigation of enteric viruses associated with poor performance or hatchery diseases in commercial poultry in southwestern Nigeria, intestinal contents from 97 condemned or runted day-old commercial turkey poults were examined for turkey astroviruses, infectious bronchitis virus, chicken astrovirus (CAstV), avian nephritis virus, avian rotavirus, avian reovirus, fowl adenovirus, and chicken parvovirus by virus isolation, electron microscopy (EM), polymerase chain reaction (PCR), and reverse transcription PCR. The samples were collected from five commercial hatcheries and five farms located in southwestern Nigeria. While all samples tested negative for other viruses, CAstV was detected in the majority $(83.5 \%)$ of the birds, although some pleomorphic virus-like particles with surface projections that appeared fringed or fimbriated were observed in five of the cell culture samples by EM. Phylogenetic analysis revealed these CAstV strains belonged to the Bi clade. These findings not only implicate $\mathrm{CAstV}$ as the major cause of hatchery condemnations in commercial turkeys in southwestern Nigeria but also highlight the need for experimental studies to further establish its role in this disease condition.
\end{abstract}

\section{Introduction}

Poultry production is a rapidly growing branch of the main food industries worldwide, projected to be the largest meat sector globally by 2020 [1]. This sector has become a diversified industry with a variety of interests such as egg and meat production as well as hatchery operations. Worldwide, poultry production has undergone rapid changes, including the intensification of production, introduction of new breeds, improved biosecurity, and preventive health measures. In

Handling Editor: Reimar Johne.

Adebowale I. Adebiyi

adebiyiade@gmail.com

1 Department of Veterinary Microbiology, University of Ibadan, Ibadan, Oyo State, Nigeria

2 Biological Sciences, Queen's University, Belfast, UK

3 Veterinary Sciences Division, Agri-Food and Biosciences Institute, Belfast, UK developing countries, however, adoption of this type of production has been limited because of the costs of infrastructure to maintain biosecurity for birds, quality hybrid chicks, balanced feed, biologics, and quality veterinary care [2]. In addition, although primary breeders of birds have eliminated vertically transmitted diseases from their elite and great-grandparent generations during the past four decades, infection of grandparent and parent stocks still occurs in many developing countries, resulting in dissemination of diseases [3].

Two major viral enteric diseases occur in poultry: poult enteritis complex in turkeys and runting-stunting syndrome in chickens, with the economic impact of these infections on the poultry industry manifesting as devastating losses, especially in young birds, with resultant growth retardation, hatchery diseases, and susceptibility to other diseases [4-6]. This is worsened by the lack of specific treatments and commercial vaccines against many of the viruses associated with these diseases.

Studies have implicated several viruses, including astroviruses, reoviruses, adenoviruses, coronaviruses, 
and rotaviruses, as causative agents of enteric infections in chickens and turkeys, which produce different clinical manifestations depending on whether they occur as single or multiple infections [4, 7-10]. These infections have considerable economic impact due to reduced weight gain and feed intake, which lead to opportunistic infections in affected birds. In addition, they usually cause a mild gastroenteritis in most species, although several reports have associated astroviruses with acute disease in the young of multiple species and more-severe diseases in poultry [8-11].

The enteric virus chicken astrovirus $(\mathrm{CAst} \mathrm{V})$ was recently shown to be the agent responsible for the hatchery disease white chick syndrome (WCS), which results in high levels of mid- and late-term death of embryos, chicks too weak to pip, and weak, white chicks that die soon after hatching. Although the initial reports were from Finland [8], WCS has since been reported from a range of countries on different continents [12-14]. The virus has been demonstrated to pass vertically from naïve breeder flocks infected during lay, resulting in hatchability drops averaging 29\% in Finland over a two-week period while the hens seroconverted [8]. Canadian researchers estimated the cost of WCS to affected Canadian hatching egg producers and hatcheries at 105,000 US dollars and 68,000 US dollars per 10,000 hens, respectively, for one outbreak [14].

The commercial poultry sector in Nigeria represents 15\% of the total poultry population and is of significant economic importance to the country and the West African subregion because of its contribution to employment, food security, and livelihoods [15]. Turkeys, which are heavy and fastgrowing birds with improved feed conversion ability, occupy an important position next to chickens in contributing to the most rapidly evolving sector, playing a significant role in augmenting the economic and nutritional status of varied populations [16]. These birds are increasingly raised for their meat, which is the leanest among the domestic avian species and can have the highest protein content, depending on the type of diet they are fed [17]. Despite the increased interest in turkey rearing, especially in southwestern Nigeria, which is regarded as the hub of commercial poultry operations in the country, there are no reports associating enteric viruses with poor performance or hatchery diseases commonly seen in commercial turkeys in Nigeria. Thus, as part of an ongoing investigation of enteric viruses associated with runting and stunting in commercial poultry in southwestern Nigeria, we examined hatchery-condemned commercial turkey poults with symptoms of weakness, dullness, depression, poor growth, ruffled/wet feathers, and splayed legs for some enteric viruses, mostly those associated with growth problems, including turkey astrovirus 1 and 2 (TAstV-1 and TAstV-2), chicken astrovirus (CAstV), avian nephritis virus (ANV), infectious bronchitis virus (IBV), avian rotavirus
(AvRV), avian reovirus (ARV), fowl adenovirus (FAdV), and chicken and turkey parvovirus.

\section{Materials and methods}

\section{Sampling}

Samples consisting of intestinal contents from 97 live, poorly performing day-old commercial turkey poults purposively collected from five commercial hatcheries and five farms in Oyo and Osun States, southwestern Nigeria, were collected and processed to give a final $10 \%(\mathrm{w} / \mathrm{v})$ suspension as described previously [10].

\section{Detection of enteric viruses from cell culture virus isolates}

Virus isolation from individual samples by means of in vitro infection of primary chicken embryo liver (CEL) cell culture prepared from 14- to 16-day-old specific-pathogenfree chicken embryos was performed as described previously [10]. Virus isolates were identified by negative staining transmission electron microscopy, and molecular analysis by RT-PCR and PCR was performed for detection of ARV [18] and FAdV [19], respectively (Table 1).

The cell culture suspension was centrifuged for $30 \mathrm{~min}$ utes at $1,500 \times g$ in a microcentrifuge, and the supernatant was discarded. The pellet was resuspended in $50 \mu \mathrm{l}$ of distilled water and mixed using a vortex mixer for 30 seconds. Then, $50 \mu \mathrm{l}$ of each test sample to be stained was placed in a well of a multi-spot slide, and a carbon-coated grid was added. This was incubated at room temperature for $10 \mathrm{~min}-$ utes. The grid was then stained in $50 \mu \mathrm{l}$ of $4 \%$ ammonium molybdate for 60 seconds and allowed to dry for 10 minutes. The grid was then examined using an electron microscope.

\section{Differential diagnosis for other enteric viruses}

Supernatants from four intestinal content samples were pooled based on location and source to give a total of 24 sample pools (Table 2), which were subjected to nucleic acid extraction. The screening procedures carried out to detect the most common enteric viruses associated with runting and stunting in poultry in southwest Nigeria [10] included real-time RT-PCR (RT-qPCR) assays for detection of IBV [20], CAstV, and ANV [21], real-time PCR for chicken and turkey parvovirus [10], and conventional RT-PCR tests for TAstV-1, TAstV-2, and AvRV [22]. Furthermore, 10 pools of RNA samples that were found by RT-qPCR to contain substantial quantities of $\mathrm{CAstV}$ were amplified by conventional RT-PCR of the ORF 2 (capsid) gene as described previously [23]. The sequences of primers and target genes 
Table 1 Primers for detection of enteric viruses in commercial turkeys with hatchery disease

\begin{tabular}{|c|c|c|c|c|}
\hline Virus & Primer & Nucleotide sequence (5'-3') & Target gene & Reference \\
\hline \multirow[t]{3}{*}{ Infectious bronchitis virus } & IBV5 F & GCTTTTGAGCCTAGCGTT & \multirow[t]{3}{*}{ S1 gene } & \multirow[t]{3}{*}{ [20] } \\
\hline & IBV5 R & GCCATGTTGTCACTGTCTATT & & \\
\hline & Probe & FAM-CACCACCAGAACCTGTCACCTC-BHQ1 & & \\
\hline \multirow[t]{3}{*}{ Chicken astrovirus } & CAstV F & GCYGCTGCTGAAGAWATA CAG & \multirow[t]{3}{*}{ Polymerase } & \multirow[t]{3}{*}[21]{} \\
\hline & CAstV R & CATCCCTCTACCAGATTTTCT GAA A & & \\
\hline & Probe & 6-FAM-CAG AAG TCG GGC CC-MGB & & \\
\hline \multirow[t]{3}{*}{ Avian nephritis virus } & ANV F & GTA AAC CAC TGG YTG GCT GAC T & \multirow[t]{3}{*}{ Polymerase } & \multirow[t]{3}{*}[21]{} \\
\hline & ANV R & TAC TCG CCG TGG CCT CG & & \\
\hline & Probe & 6-FAM-CAG CAA CTG ACT TTC-MGB & & \\
\hline \multirow[t]{2}{*}{ Turkey astrovirus 1} & TAstV-1 F & AGCTYATGMGGTTCTTTCTTCTYG & \multirow[t]{2}{*}{ Polymerase } & \multirow[t]{2}{*}[22]{} \\
\hline & TAstV-1 R & GATGGTGGGTAGCCTATTGTGTTC & & \\
\hline \multirow[t]{2}{*}{ Turkey astrovirus 2} & TAstV-2 F & TGGACCGACCCRRTTTTYACCA & \multirow[t]{2}{*}{ Polymerase } & \multirow[t]{2}{*}[22]{} \\
\hline & TAstV-2 R & GGCCCGACYTCAGGMAGTTGT & & \\
\hline \multirow[t]{2}{*}{ Avian rotavirus } & $\operatorname{AvRV}(\mathrm{ROT}) \mathrm{F}$ & GGG CGT GCG GAA AGA TGG AGA AC & \multirow[t]{2}{*}{ NSP4 } & \multirow[t]{2}{*}[22]{} \\
\hline & $\operatorname{AvRV}(\mathrm{ROT}) \mathrm{R}$ & GGG GTT GGG GTA CCA GGG ATT AA & & \\
\hline \multirow[t]{2}{*}{ Avian reovirus } & ARV (Reo) P1F & AGT ATT TGT GAG TAC GAT TG & \multirow[t]{2}{*}{ Sigma C } & \multirow[t]{2}{*}[18]{} \\
\hline & ARV (Reo) P4R & GGC GCC ACA CCT TAG GT & & \\
\hline \multirow[t]{2}{*}{ Chicken astrovirus } & CAstV (pre cap) F & TAG AGG GAT GGA CCG AAA TAT AGC AGC & \multirow[t]{2}{*}{ ORF 2 (capsid) } & \multirow[t]{2}{*}{ [23] } \\
\hline & CAstV (post cap) R & TGC AGC TGT ACC CTC GAT CCTA & & \\
\hline \multirow[t]{2}{*}{ Fowl adenovirus } & FAdV $\operatorname{Hex}(\mathrm{A}) \mathrm{F}$ & CAA RTT CAG RCA GAC GGT & \multirow[t]{2}{*}{ Hexon } & \multirow[t]{2}{*}{ [19] } \\
\hline & FAdV $\operatorname{Hex}(B) R$ & TAG TGA TGM CGS GAC ATC AT & & \\
\hline
\end{tabular}

Table 2 Quantification of CAstV in commercial turkeys in southwest Nigeria

\begin{tabular}{llllllll}
\hline Sample & Location & Source & CAstV log value & Sample & Location $^{\#}$ & Source $^{\#}$ & CAstV log value \\
\hline VF18-p41 & Ibadan & H/a & 3.28 & VF18-p53 & Ibadan & H/c & 4.05 \\
VF18-p42 & Ibadan & H/a & 5.70 & VF18-p54 & Ibadan & H/c & 2.29 \\
VF18-p43 & Ibadan & H/b & 2.89 & VF18-p55 & Ibadan & H/c & 2.32 \\
VF18-p44 & Ibadan & SF/a & 2.57 & VF18-p56 & Ibadan & H/d & 2.45 \\
VF18-p45 & Ibadan & SF/a & 5.19 & VF18-p57 & Ikirun & SF/d & 4.80 \\
VF18-p46 & Ibadan & SF/a & 4.47 & VF18-p58 & Ikirun & SF/d & 4.95 \\
VF18-p47 & Ibadan & SF/a & 3.45 & VF18-p59 & Ikirun & SF/e & 4.79 \\
VF18-p48 & Ibadan & SF/b & 3.33 & VF18-p60 & Ibadan & H/d & 4.39 \\
VF18-p49 & Ibadan & SF/b & 1.75 & VF18-p61 & Ibadan & H/e & 3.38 \\
VF18-p50 & Ibadan & SF/b & 1.91 & VF18-p62 & Ibadan & H/e & 3.64 \\
VF18-p51 & Ibadan & SF/c & 1.56 & VF18-p63 & Ibadan & H/e & 5.10 \\
VF18-p52 & Ibadan & SF/c & 1.94 & VF18-p64 & Ibadan & H/c & 6.22 \\
\hline
\end{tabular}

Log values are viral RNA copy numbers expressed as base 10 logarithmic values. All samples were from day-old runted commercial poultry poults

\#Upper-case letters denote different poultry establishments (H, hatchery; SF, smallholder farm), and lowercase letters indicate different farms/flocks. Values below 2 are considered negative, as they are below the reproducible lower detection limit of the CAstV real-time RT-qPCR test used for RT-PCR and PCR assays in this study are shown in Table 1.

Target-size (2.2 kbp) amplicons for CAstV were excised from a minimal gel area and purified using a PureLink extraction kit (Thermo Fisher Scientific, Paisley, UK). The PCR products were sequenced commercially across the entire capsid gene. Subsequently, primer walking was performed on the entire capsid sequence. Analysis of sequencing data and multiple alignments were performed using MUSCLE software [24].

The complete nucleotide sequence of the CAstV capsid gene was compared with reference sequences in the GenBank database using a Basic Local Alignment Search Tool [25] nucleotide (BLASTn) megablast search via the 
NCBI (National Center for Biotechnology Information) website. An unrooted phylogenetic tree based on complete nucleotide sequences of the $\mathrm{CAstV}$ capsid gene was constructed using the Jukes-Cantor distance model and the neighbor-joining [26] algorithm with 1,000 bootstrap replicates in Geneious version 10.2 Software (Biomatters, Auckland, New Zealand). The sequences of the reference strains determined were obtained from the GenBank [27] database. The $\mathrm{CAstV}$ nucleotide sequences obtained in this study, designated NGR_CAstV_tk1 and NGR_CAstV_tk2, are the 5' and 3' regions of the same CAstV strain, and they were submitted to the GenBank database under accession numbers MK509016 and MK509017, respectively. Furthermore, the full-length CAstV capsid sequence (accession number MW446478) from the sample pool with the highest $\log _{10}$ value was determined in both directions.

\section{Results}

\section{Detection of enteric viruses from cell culture virus isolates}

Cell detachment and death at various passage levels in infected CEL cell cultures were observed in five (four from Oyo and one from Osun) of the 97 individual samples. Under negative-stained transmission electron microscopy, pleomorphic virus-like particles with a mean diameter of approximately $170 \mathrm{~nm}$ and a range of $168-174 \mathrm{~nm}$ were seen (Fig. 1). The particles appeared fringed or fimbriated with surface projections and resembled coronaviruses with some semblance of spikes on the outer edge of the particle.

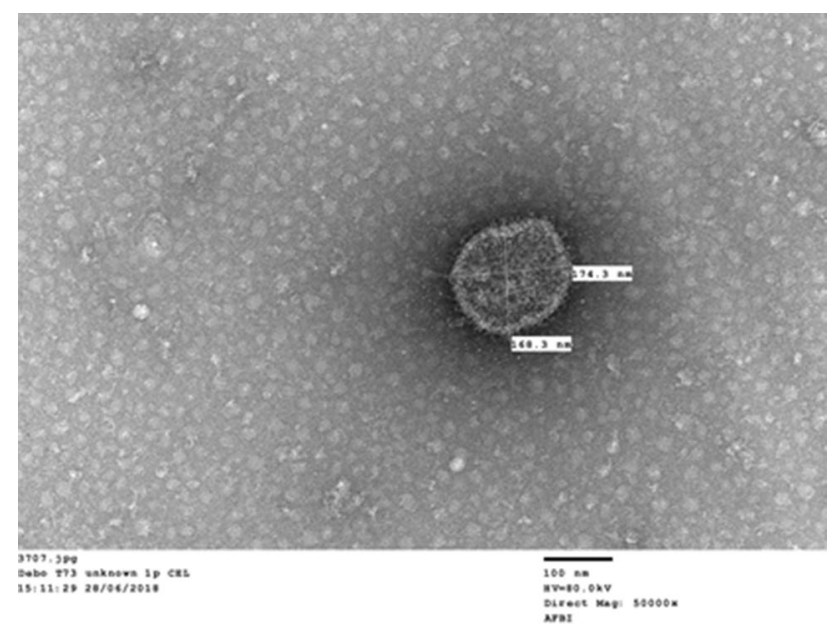

Fig. 1 Pleomorphic virus-like particle with surface projections observed by transmission electron microscopy
Molecular detection and characterization of enteric viruses

By RT-qPCR and qPCR, all pooled samples were negative for ANV, IBV, and chicken and turkey parvovirus, while 20 out of the 24 pools were positive for $\mathrm{CAstV}$, with RNA $\log _{10}$ values ranging from 2.29 to 6.22 (Table 2). One pool was considered to have a high (>6.0) RNA $\log _{10}$ value, followed by nine pools with moderate (4.0-6.0) RNA $\log _{10}$ values and the majority $(10 / 20)$ with low $(<4.0)$ RNA $\log _{10}$ values as described by Smyth et al. [21]. In addition, using conventional assays, all of the samples tested negative for TAstV-1, TAstV-2, AvRV, ARV, and FAdV. Conventional RT-PCR for the $\mathrm{CAstV}$ capsid gene was applied to 10 of the 20 pooled samples that were positive by CAstV RT-qPCR (i.e., those with RNA $\log _{10}$ values of 4.0 to $>6.0$ ) yielded only one capsid gene product suitable for sequencing from the sample pool with the highest $\log _{10}$ value, which was excised from the gel, purified and sequenced commercially across the entire capsid gene.

Based on analysis of the capsid gene, a multiple sequence alignment of the entire CAstV capsid nucleotide sequence (MW446478_NGR_Tk2) showed it to be 94.8-100\% identical to those of subgroup Bi [23] CAstVs (Fig. 2). The strain detected in the condemned turkey poults in this study was 91\% identical to strains FP3 and 11672 in its capsid gene nucleotide sequence and $96.5 \%$ and $96.7 \%$ identical to FP3 and 11672 , respectively, in its capsid protein amino acid sequence.

The Nigerian CAstV strain from the turkey poults had the highest amino acid sequence identity values of $100 \%$ at the $\mathrm{N}$-terminus and $99.4 \%$ at the C-terminus to the CAstV strains NGR-CAstV-Ch1 and NGR-CAstV-Ch2, which were detected earlier in commercial broilers in Southwest Nigeria [10]. In addition, a multiple sequence alignment of the fulllength capsid sequence showed that the nucleotide sequence of the capsid gene of the poult CAstV was $99.1 \%$ identical to that of the chick strain (19 mutations, 17 of which were silent and only 2 non-silent), and the amino acid sequences were $99.7 \%$ identical.

\section{Discussion}

Enteric viruses in commercial poultry cause considerable economic losses due to poor feed conversion, decreased body weight, lower uniformity at slaughter, reduced viability, hatchery condemnations, and secondary diseases. Previously, we reported the detection of some enteric viruses, chiefly CAstV, associated with runting and stunting in dayold chicks and older broilers in southwestern Nigeria [10]. In the present study, 97 condemned commercial day-old turkey poults from five different hatcheries and five farms in 


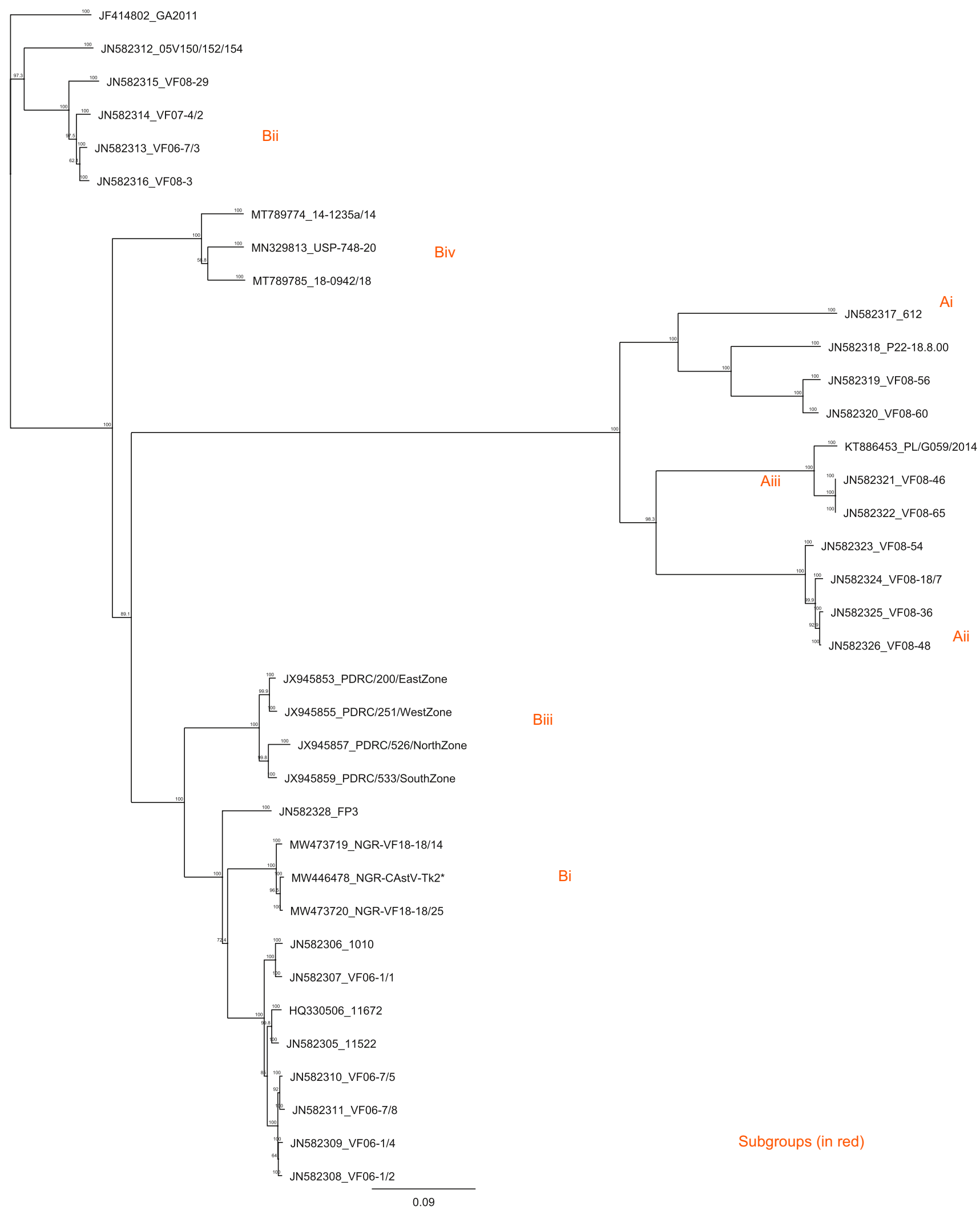

Fig. 2 Unrooted phylogenetic tree based on nucleotide sequences of the CAstV capsid gene. The CAstV sequence identified in Nigerian turkey poults is indicated by an asterisk. Subgroup clustering of the serologically distinct CAstV A and B groups is shown (red colour) 
southwestern Nigeria were investigated for a range of enteric viruses commonly associated with hatchery condemnations.

Electron microscopic images of negatively stained virus isolates from five individual poults revealed pleomorphic virus-like particles that appeared fringed or fimbriated with surface projections resembling those of coronaviruses, but interestingly, the samples tested negative for infectious bronchitis virus (a coronavirus of poultry) by real-time RT-PCR. Similar particles had been reported in the faeces of diseased game birds with clinical signs of stunting and scour [28], and it was speculated that they may be specific for a particular condition and of diagnostic value. Therefore, the detection of fimbriated virus-like particles with unique morphology in runted day-old commercial turkey poults in this study is suggestive of a hitherto uncharacterized virus needing further confirmation. However, the small number of samples positive for this virus suggests that it is not the main aetiological agent.

Furthermore, the identification of CAstV as the only detected virus in the majority of the hatchery-condemned turkey poults corroborates the suggestion that astroviruses are the most common enteric viruses detected in intestinal samples of poults [4, 29]. It also supports the earlier proposition that CAstV is widely associated with runting-stunting syndrome and hatchery condemnations in commercial poultry in southwestern Nigeria [10]. Since vaccination against CAstV is not practised in commercial poultry in Nigeria, its detection suggests natural exposure and susceptibility of turkeys to infection with the virus. This is similar to a report of CAstV in turkeys with poor productivity in the USA [4].

External egg contamination has been reported to be an unlikely source of virus infection due to poor virus survival at the temperatures and humidity levels set for incubation of eggs [30]. Similarly, Adene [31] has noted that a breached or low hygiene standard of incubators, hatchers, and other components of hatcheries usually involves bacterial and fungal contamination. Thus, our detection of CAstV RNA in day-old turkeys suggests possible vertical transmission from infected in-lay parent birds with the consequence that poults may hatch shedding the virus. Additionally, astrovirus infection has been reported to cause decreased growth due to malabsorption in hatchling turkey poults with transient maldigestion [32].

It has been reported that the broad range of species infected, apparent viral genetic diversity, and occurrence of recombination events indicate cross-species transmission and subsequent adaptation of astroviruses to new hosts and/ or coinfection of the same host with different astroviruses [33]. This is consistent with the detection of CAstV in the majority of the pools of turkey poults, with more than $83 \%$ positive at levels ranging from low to moderate. There is a wide range of sequence identities shown in the phylogenetic tree (Fig. 2), reaching below 50\% with the A group strains, which reflects the diversity of strains in circulation in poultry flocks and highlights the significance of an almost identical match with the strain detected in many condemned Nigerian chick pools [10]. Sequencing of the entire capsid gene confirmed this to be the same strain that was detected in the chicks.

This high degree of genetic conservation in a virus that is known to be highly diverse, with multiple strains in circulation, strongly suggests significance in the hatchery condemnation and runting of the turkey poults and furthermore demonstrates cross-species infection, as has been reported previously. These findings may be an indication of crossspecies spread of the virus as a result of the common practice of rearing commercial chickens with turkeys in the study area, and it further supports the ICTV decision on alternative nomenclature and taxonomic classification for this virus family, as was proposed recently by the Astroviridae Study Group [34], to reclassify avian astroviruses without host names. In addition, this finding supports the postulation that broiler birds, and perhaps turkeys, are more susceptible to the effects of vertically transmitted virus at the early post-hatch period $[35,36]$ and suggests that early exposure to $\mathrm{CAstV}$ may have a negative impact on commercial turkey production, although further investigative studies are needed to fully evaluate the significance of CAstV infection in turkeys.

Many strains of CAstV are probably apathogenic, but specific strains are known to cause hatchery disease: for example, the B iv CAstV strain responsible for cases of WCS [8], the Bi CAstV FP3 isolate, originally obtained during an investigation of early broiler mortality in the United Kingdom [37], and the Bi CAstV 11672 virus obtained from day-old chicks as part of investigation of hatchability problems in the United Kingdom [38]. The strain detected in the condemned turkey poults in this study also belongs to the Bi subgroup and is $91 \%$ identical to the FP3 and 11672 isolates in its capsid gene nucleotide sequence and $96.5 \%$ and $96.7 \%$ identical to the FP3 and 11672 isolate, respectively, in its capsid protein amino acid sequence. The poult CAstV strain identified in this study is essentially identical (99.1\% and $99.7 \%$ based on full-length capsid nucleotide and amino acid sequence comparisons, respectively) to the CAstV strain detected in multiple cases of chick hatchery condemnations in southwestern Nigeria due to runting and poor thrift [10], and this high level of homology to strains associated with hatchery diseases in chicks suggests the presence of a pathogenic strain in poults, potentially vertically transmitted.

In conclusion, the findings of this study reveal for the first time the involvement of CAstV in hatchery condemnations of commercial turkey poults in southwestern Nigeria and highlight the need for continuous monitoring of CAstV infection in the study area to ascertain its true impact on the 
poultry industry. In addition, the role of $\mathrm{CAstV}$ in relation to hatchery disease should be evaluated by experimental infection of turkey poults in order to establish their susceptibility to this virus.

Acknowledgements We appreciate the poultry farmers and hatchery personnel for allowing collection of samples.

Author contributions Conceptualization: AIA, DOO and VJS. Methodology: AIA, KM and VJS. Validation: AIA and VJS. Writing/preparation of original draft: AIA. Supervision: DOO and VJS. All authors read and approved the final draft.

Funding This work received no specific grant from any funding agency.

Availability of data and materials All data generated or analysed during this study are included in this published article. The raw data are available from the authors upon request.

\section{Declarations}

Conflict of interest The authors declare that they have no conflict of interest.

Ethical approval This study was approved by the University of Ibadan Animal Care and Use Research Ethics Committee (UIACUREC/18/0116).

Consent to participate The farm owners and hatchery personnel voluntarily consented to sample collection.

\section{References}

1. Abdul-Cader MS, Palomino-Tapia V, Amarasinghe A, AhmedHassanm H, Senapathi UD, Abdul-Careem MF (2018) Hatchery vaccination against poultry viral diseases: potential mechanisms and limitations. Viral Immunol 31(1): 23-33

2. Permin A, Pedersen G (2002) The need for a holistic view on disease problems in free-range chickens. In: Characteristics and parameters of family poultry production in Africa. International Atomic Energy Agency, Vienna, pp 9-13

3. Shane SM (2005) Handbook on poultry diseases, 2nd edn. American Soybean Association, St. Louis

4. Pantin-Jackwood MJ, Day JM, Jackwood MW, Spackman E (2008) Enteric viruses detected by molecular methods in commercial chicken and turkey flocks in the United States between 2005 and 2006. Avian Dis 52:235-244

5. Mettifogo E, Nunez LF, Chacon JL, Santader-Parra SH, AstolfiFerreira CS, Jerez JA, Jones RC, Piantino Ferreira AJ (2014) Emergence of enteric viruses in production chickens is a concern for avian health. Sci World J 2014:450423

6. De-la Torre DI, Nunez LF, Astolfi-Ferreira CS, Piantino Ferreira AJ (2018) Enteric virus diversity examined by molecular methods in Brazilian poultry flocks. Vet Sci 5:38

7. Jindal N, Patnayak DP, Chander Y, Ziegler AF, Goyal SM (2010) Detection and molecular characterization of enteric viruses in breeder turkeys. Avian Pathol 39:53-61

8. Smyth VJ, Trudgett J, Wylie M, Jewhurst H, Conway B, Welsh M, Kaukonen E, Perko-Mäkelä P (2013) Chicken astrovirus detected in hatchability problems associated with "white chicks". Vet Rec 173:403-404

9. Awe OO, Kang KI, Ibrahim M, Ali A, Elaish M, Saif YM, Lee CW (2015) Age-related susceptibility of turkeys to enteric viruses. Avian Dis 59:207-212

10. Adebiyi AI, Tregaskis PL, Oluwayelu DO, Smyth VJ (2019) Investigation of enteric viruses associated with runting and stunting in day-old and older broilers in Southwest Nigeria. Front Vet Sci 6:239

11. Matsui SM, Greenberg HB (2001) Astroviruses. In: Knipe DM, Howley PM (eds) Fields virology, vol 1, 4th edn. Lippincott. Williams \& Wilkins, Baltimore, pp 875-893

12. Nunez LFN, Santander Parra SH, Carranza C, Astolfi-Ferreira CS, Buim MR, Piantino Ferreira AJ (2016) Detection and molecular characterization of chicken astrovirus associated with chicks that have an unusual condition known as "white chicks" in Brazil. Poult Sci 95:1262-1270

13. Sajewicz-Krukowska J, Pac K, Lisowska A, Pikula A, Minta Z, Kroliczewska B, Domanska-Blicharz K (2016) Astrovirus induced "white chicks" condition-field observation, virus detection and preliminary characterization. Avian Pathol 45:2-12

14. Long KE, Hastie GM, Ojkic D, Brash MI (2017) Economic impacts of white chick syndrome in Ontario, Canada. Avian Dis 61:402-408

15. FAOSTAT (2014) Food and Agriculture Organization.org. FAOSTAT, Geneva. http://faostat3.fao.org/download/Q/QA/E. Accessed 15 May 2018

16. CPDO (2014) Central Poultry Development Organization. Turkey-Management Guide. Department of Animal Husbandry and Dairying, Ministry of Agriculture, India

17. Ogunmola OO, Taiwo OO, Ayankoso AS (2013) The nutritive value of the meat quality of locally bred chicken, exotic chicken and turkey. J Appl Chem 3:46-50

18. Kant A, Blak F, Born L (2003) Classification of Dutch and German avian reoviruses by sequencing the $\sigma \mathrm{C}$ proteins. Vet Res $34: 203-212$

19. Meulemans G, Boschmans M, Berg VD, Decaesstecker M (2001) Polymerase chain reaction combined with restriction enzyme analysis for detection and differentiation of fowl adenoviruses. Avian Pathol 30:655-660

20. Callison SA, Hilt DA, Boynton TO, Sample BF, Robison R, Swayne DE, Jackwood MW (2006) Development and evaluation of a real-time Taqman RT-PCR assay for the detection of infectious bronchitis virus from infected chickens. J Virol Methods 138:60-65

21. Smyth VJ, Jewhurst HL, Wilkinson D, Adair B, Gordon A, Todd D (2010) Development and evaluation of real-time TaqMan ${ }^{\circledR}$ RT-PCR assays for the detection of avian nephritis virus and chicken astrovirus in chickens. Avian Pathol 39:467-474

22. Day JM, Spackman E, Pantin-Jackwood M (2007) A multiplex RT-PCR test for the differential identification of turkey astrovirus type 1 , turkey astrovirus type 2 , chicken astrovirus, avian nephritis virus, and rotavirus. Avian Dis 51:681-684

23. Smyth VJ, Todd D, Trudgett J, Lee A, Welsh MD (2012) Capsid protein sequence diversity of chicken astrovirus. Avian Pathol 41:151-159

24. Edgar RC (2004) MUSCLE: multiple sequence alignment with high accuracy and high throughput. Nucleic Acids Res 32(15):1792-1797. https://doi.org/10.1093/nar/gkh340

25. Altschul SF, Gish W, Miller W, Myers EW, Lipman DJ (1990) Basic local alignment search tool. J Mol Biol 215:403-410

26. Saitou N, Nei M (1987) The neighbor-joining method: a new method for reconstructing phylogenetic trees. Mol Biol Evol 4:406-425

27. Benson DA, Cavanaugh M, Clark K, Karsch-Mizrachi I, Lipman DJ, Ostell J, Sayers EW (2013) GenBank. Nucleic Acids Res 
41(Database issue):D36-42. https://doi.org/10.1093/nar/gks11 95

28. Gough RE, Collins MS, Alexander DJ, Cox WJ (1990) Viruses and virus-like particles detected in samples from diseased game birds in Great Britain during 1988. Avian Pathol 19:331-342

29. Moura-AlvarezJ CJV, Scanavini LS, Nunez LFN, Astolfi-Ferreira CS, Jones RC, Piantino Ferreira AJ (2013) Enteric viruses in Brazilian turkey flocks: single and multiple virus infection frequency according to age and clinical signs of intestinal disease. Poult Sci 92:945-955

30. Calnek BW, Hitchner SB (1973) Survival and disinfection of Marek's disease virus and the effectiveness of filters in preventing airborne dissemination. Poult Sci 52:35-43

31. Adene DF (2004) Poultry health and production: principles and practices. Stirling-Holden Press, Ibadan, pp 55-58

32. Thouvenelle ML, Reynolds DL, Haynes JS (1993) Astrovirus infection in hatching turkeys. Poult Digest 52(3):13-16

33. Benedicts PD, Schultz-Cherry S, Burnham A, Cattoli G (2011) Astrovirus infections in humans and animals: Molecular biology, genetic diversity, and interspecies transmissions. Infect Gen Evol 11:1529-1544

34. Bosch A, Guix S, Krishna NK, Mendez E, Mouane SS, PantinJackwood M, Schultz-Cherry S (2010) Three new species in the genus Avastrovirus in the Astroviridae family, ICTV 2010.017abV
35. Biđin M, Lojkic I, Biđin Z, Tiljar M, Majnaric D (2011) Identification and phylogenetic diversity of parvovirus circulating in commercial chicken and turkey flocks in Croatia. Avian Dis 55:693-696

36. Koo BS, Lee HR, Jeon EO, Han MS, Min KC, Lee SB, Mo IP (2013) Molecular survey of enteric viruses in commercial chicken farms in Korea with a history of enteritis. Poult Sci 92:2876-2885

37. Spackman D, Gough RE, Collins MS, Lanning D et al (1984) Isolation of an enterovirus-like agent from the meconium of deadin-shell chicken embryos. Vet Rec 114:216-218

38. Todd D, Wilkinson DS, Jewhurst HL, Wylie M, Gordon AW, Adair BM (2009) A seroprevalence investigation of chicken astrovirus infections. Avian Pathol 38:301-309

Publisher's Note Springer Nature remains neutral with regard to jurisdictional claims in published maps and institutional affiliations. 